\title{
Características das Carcaças, Biometria do Trato Gastrintestinal, Tamanho dos Órgãos Internos e Conteúdo Gastrintestinal de Bovinos F1 Simental x Nelore Alimentados com Dietas contendo Vários Níveis de Concentrado
}

\section{Marcelo de Andrade Ferreira ${ }^{1}$, Sebastião de Campos Valadares Filho ${ }^{2}$, Elaine Barbosa Muniz ${ }^{3}$, Antônia Sherlânea Chaves Veras ${ }^{1}$}

\footnotetext{
RESUMO - A utilização de diferentes níveis de concentrado na ração $(25 ; 37,5 ; 50 ; 62,5$; e 75\%) foi avaliada sobre as características da carcaça, o peso dos compartimentos do trato gastrintestinal, o peso dos órgãos internos e o conteúdo do trato gastrintestinal, de 24 bovinos mestiços Simental x Nelore, não-castrados, com 17 meses de idade e peso vivo médio de $354 \mathrm{~kg}$. Os animais foram abatidos quando atingiram $500 \mathrm{~kg}$ de peso vivo. Após o resfriamento, as carcaças foram avaliadas qualitativa (área de olho de lombo) e quantitativamente (medições, rendimentos e cortes básicos). O rendimento da carcaça e dos cortes básicos, a área de olho de lombo e as proporções de músculo e gordura não foram influenciados pelos níveis de concentrado, enquanto o comprimento de carcaça diminuiu linearmente com o aumento do nível de concentrado. O conteúdo do trato gastrintestinal diminuiu linearmente com a adição de concentrado na ração. Não houve efeito dos níveis de concentrado nos pesos de coração, pulmão e rúmen-retículo. Os pesos de fígado, rins, baço, abomaso, intestino delgado e gordura interna aumentaram e o do omaso diminuiu linearmente com a adição de concentrado na dieta.
}

Palavras-chave: carcaça, composição física, concentrado, cortes básicos, conteúdo gastrintestinal, órgãos internos

\section{Carcass Characteristics, Gastrointestinal Tract Biometry, Internal Organs Weight and Gastrointestinal of F1 Simental x Nellore Bulls Fed Diets with Different Concentrate Levels}

\begin{abstract}
The effect of different dietary concentrate levels $(25,37.5,50,62.5$, and 75\%) on the carcass characteristics, gastrointestinal tract weight, internal organ weight and gastrointestinal tract fill was evaluated. Twenty-four F1 Simental x Nellore bulls, with 17 months of age and average live weight of $354 \mathrm{~kg}$, were used. The animals were slaughtered when reached $500 \mathrm{~kg}$ of live weight After cooling, carcasses were qualitative (loin eye area) and quantitatively (measures, yields and prime cuts) evaluated. The carcass and prime cuts dressing, the loin eye area and the muscle and fat contents were not affected by the concentrate levels, while the carcass length linearly decreased as concentrate level increased. The gastrointestinal tract fill linearly decreased as dietary concentrate level increased. There was no effect of concentrate level on the heart, lungs and rumen-reticulum weights. The weights of liver, kidney, spleen, abomasum, small intestine and internal fat increased and the weight of the omasum linearly decreased as dietary concentrate levels increased.
\end{abstract}

Key Words: carcass, concentrate, gastrointestinal tract, internal organs, physical composition, prime cuts

\section{Introdução}

A necessidade de aumentar a eficiência dos sistemas de produção de proteína de origem animal é premente, em razão, principalmente, do crescimento da população mundial. O confinamento caracterizase como uma tecnologia de ponta neste intento. Porém, o desempenho animal é variável e dependente de fatores inerentes ao próprio animal, como raça, sexo e idade, assim como externos, em que a quantidade e qualidade da ração são fundamentais (PRESTON e WILLIS, 1982).
No Brasil, a comercialização de bovinos para corte é realizada por intermédio do peso vivo ou do rendimento (peso da carcaça), o que desestimula os produtores a realizarem investimentos na pecuária de corte, uma vez que a não preocupação com a qualidade e quantidade da porção comestível torna inexistente a diferenciação de preços e aumenta a margem de riscos, dificultando o retorno do capital investido (JORGE, 1993).

Os cortes básicos da carcaça de bovinos no mercado brasileiro são o dianteiro com cinco costelas, compreendendo o acém e a paleta completos, o

\footnotetext{
${ }_{1}$ Professor do Depto. de Zootecnia da UFRPE. E.mail: mcelo@yahoo.com

2 Professor Titular da Universidade Federal de Viçosa.

3 Zootecnista/ESAL.
} 
costilhar ou ponta de agulha e o traseiro especial ou serrote, que inclui o coxão e a alcatra completa (PERON et al., 1993a). Economicamente, seria desejável maior rendimento do traseiro especial em relação a outros cortes, devido a seu maior valor comercial (BERG e BUTTERFIELD, 1976).

No estudo de carcaças bovinas, o rendimento das mesmas é, geralmente, o primeiro índice a ser considerado, expressando a relação percentual entre os pesos da carcaça e o do animal (PERON et al., 1993a).

$\mathrm{O}$ rendimento de carcaça está sujeito à grande variação, por influência de diversos fatores, de forma que valores diferentes serão obtidos, se o rendimento for calculado em relação ao peso vivo ou ao peso de corpo vazio (livre da digesta). Os valores com base no peso vivo são afetados pelo tempo de jejum e tipo de dieta (GEAY, 1975). PRESTON e WILLIS (1982) mostraram que o rendimento de carcaça aumenta com o peso de abate e o nível de engorda.

As funções primárias do trato gastrintestinal e de seus órgãos acessórios são a digestão e a absorção de nutrientes essenciais para os processos metabólicos (SIGNORETTI et al., 1996).

No Brasil, existem poucos estudos relativos ao desenvolvimento do trato gastrintestinal (TGI) e tamanho dos órgãos internos dos animais domésticos (JORGE et al., 1997; SIGNORETTI et al., 1996; OLIVEIRA et al., 1994; e PERON et al., 1993b). O estudo de partes não-integrantes da carcaça é importante, pois estas têm influência direta sobre o rendimento da carcaça (OLIVEIRA et al., 1994). Além disso, as diferenças no tamanho relativo dos órgãos podem estar associadas às diferenças nas exigências de mantença (SMITH e BALDWIN, 1974). SMITH e BALDWIN (1974) demonstraram que fígado, coração, glândulas mamárias e tecidos do trato gastrintestinal estão entre as partes de maior atividade metabólica nos animais. FERRELL et al. (1976), avaliando as exigências de novilhas em diferentes estágios de gestação, observaram que os órgãos internos de novilhas de raças leiteiras (Jersey e Holandês) são, proporcionalmente, maiores que os de novilhas de corte (Hereford). Concluíram, ainda, que o total de energia para mantença exigido pelo tecido muscular é menor que o da energia exigida pelos órgãos internos, o que explica as maiores exigências para mantença de novilhas leiteiras.

Em raças com aptidão leiteira, os maiores depósitos de gordura encontram-se nos tecidos que não fazem parte da carcaça, como os órgãos e as vísceras, diferentemente das tradicionais raças de corte, em que os depósitos periféricos são mais pronunciados, ocasionado menor exigência para mantença destes últimos (OWENS et al., 1995). Os órgãos viscerais apresentam elevadas taxas metabólicas e, principalmente, o fígado e o trato gastrintestinal respondem a alterações na ingestão de alimentos (FERRELLL e JENKINS, 1998) e, juntamente com o aumento no tamanho dos órgãos internos (FOX et al., 1992), respondem em parte pelos maiores requerimentos de animais com potencial para elevada produção de leite. CATTON e DHUYVETTER (1997) relataram que os tecidos viscerais, embora em menor proporção no corpo dos animais, são de considerável importância para os requisitos energéticos de mantença, pois consomem cerca de $50 \%$ do total desta energia.

LUNT et al. (1986), trabalhando com novilhos Angus Brahman x Angus e Brahman x Hereford, alimentados com forragens ou dietas à base de grãos, observaram que os fatores raça, ganho de peso diário e dieta afetaram a massa de órgãos internos e a relação entre seu peso e o peso vivo. Novilhos Angus apresentaram coração e pulmões maiores que os de Brahman x Angus, enquanto novilhos alimentados com forragens, maiores massa de coração e fígado que os alimentados com dietas à base de grãos.

PERON et al. (1993a) compararam bovinos abatidos ao início do experimento (mais leves) com animais submetidos à restrição alimentar ou alimentados à vontade (mais pesados) e concluíram que o regime alimentar influenciou o peso do TGI, que foi menor em animais submetidos à restrição alimentar. JORGE et al. (1997) também observaram redução nos pesos dos compartimentos do TGI e do fígado de bovinos submetidos à restrição alimentar.

O tamanho do fígado de novilhos respondeu rapidamente às mudanças de consumo alimentar, apresentando desenvolvimento linear em resposta ao aumento no consumo de energia metabolizável (JOHNSON et al., 1990).

O conteúdo do TGI é medido com o abate dos animais após jejum prévio por período de 16 a 24 horas. A determinação pode ser feita, diretamente, pela diferença dos pesos do TGI cheio e após o seu esvaziamento e limpeza ou, indiretamente, pela diferença entre o peso vivo e o peso de corpo vazio, sendo este obtido pela soma dos vários componentes do corpo, livre do conteúdo gastrintestinal (LANA et al., 1992).

O conteúdo do TGI pode ser influenciado pelo peso corporal, pela raça do animal, pelo estado fisiológico e pelo tipo de alimento (AGRICULTURAL RESEARCH COUNCIL - ARC, 1980). Sua variação representa a maior fonte de erros na determinação 
1176 Rev. bras. zootec.

do ganho de peso vivo (LOFGREEN e HULL, 1962).

O presente trabalho foi conduzido para verificar a influência de cinco níveis de concentrado na dieta sobre o rendimento de carcaça e de seus cortes básicos, o comprimento e a composição física da carcaça, o desenvolvimento dos compartimentos do trato gastrintestinal, o conteúdo do trato gastrintestinal e o desenvolvimento da massa de orgãos internos de bovinos $\mathrm{F}_{1}$ Simental x Nelore.

\section{Material e Métodos}

O experimento foi conduzido na área de confinamento experimental do Departamento de Zootecnia da Universidade Federal de Viçosa. Foram utilizados 24 bovinos $F_{1}$ Simental x Nelore, não-castrados, com idade média de 17 meses e peso vivo inicial de $354 \mathrm{~kg}$, distribuídos em cinco tratamentos, definidos de acordo com a proporção de concentrado na ração: $\mathrm{T}_{1=} 25 \%, \mathrm{~T}_{2}=37,5 \%, \mathrm{~T}_{3}=50 \%, \mathrm{~T}_{4}=62,5 \% \mathrm{e} \mathrm{T}_{5}=75 \%$. Para o $\mathrm{T}_{4}$ foram utilizadas quatro repetições e para os demais tratamentos, cinco, devido à morte de um animal. Como volumoso, foram utilizados, em proporções iguais, os fenos de coast-cross (Cynodon dactilum) e braquiária (Brachiaria decumbens). $\mathrm{O}$ arraçoamento foi feito na forma de ração completa e as rações experimentais (feno + concentrado) foram formuladas de acordo com o CNCPS (BARRY et al., 1994) e suas composições encontram-se na Tabela 1.

As determinações de matéria seca (MS), proteína bruta $(\mathrm{PB})$ e fibra em detergente neutro (FDN) foram feitas conforme técnicas descritas por SILVA (1990). Os teores de nutrientes digestíveis totais (NDT) foram obtidos do experimento de TIBO (1999).

Os animais foram alimentados à vontade, uma vez ao dia, pela manhã, e pesados no início do experimento e a cada 28 dias. À medida que um animal se aproxima- va do peso de abate preestabelecido, que foi de $500 \mathrm{~kg}$, as pesagens eram realizadas em intervalos menores, de $14 \mathrm{em} 14$ dias. Antes do abate, os animais foram pesados após jejum de, aproximadamente, 16 horas. Os animais eram privados apenas da ração, tendo livre acesso à água.

Após o abate, o trato gastrintestinal foi esvaziado e lavado. O trato gastrintestinal, bem como todas as outras partes do corpo do animal, foram pesados para obtenção do peso de corpo vazio (peso vivo menos o conteúdo do trato gastrintestinal). As duas meiacarcaças foram pesadas quentes e congeladas por 18 horas à temperatura de $-5^{\circ} \mathrm{C}$.

Após esse período, as meia-carcaças foram pesadas e, da meia-carcaça direita, foram retirados os cortes básicos e determinados seus pesos, para posterior avaliação. Da meia carcaça esquerda foi coletada amostra correspondente à seção da 9 a a $11^{\text {a }}$ costelas, para determinação das proporções de músculo, gordura e ossos da carcaça, de acordo com HANKIS e HOWE (1946).

Os rendimentos da carcaça foram determinados em relação ao peso vivo e peso de corpo vazio. Os rendimentos dos cortes básicos foram determinados em relação ao peso da carcaça. Em relação aos cortes básicos, o dianteiro foi separado do traseiro entre a quinta e sexta costelas. O dianteiro compreendeu o acém e a paleta completos. $O$ traseiro total foi dividido em ponta de agulha e traseiro especial, compreendendo o coxão e a alcatra completa.

De cada animal abatido, foram pesadas e coletadas amostras de cabeça, couro, pés, rúmen, retículo, omaso, abomaso, intestino delgado, intestino grosso, gordura interna (cavitária e visceral), coração, rins, fígado, baço, pulmão, língua, sangue, esôfago, traquéia e aparelho reprodutor.

O delineamento experimental foi o inteiramente casualizado e os dados, avaliados por meio de análises de variância e regressão.

Tabela 1 - Teores de matéria seca (MS), proteína bruta (PB), extrato etéreo (EE), fibra em detergente neutro (FDN) e nutrientes digestíveis totais (NDT) das rações experimentais

Table 1 - Contents of dry matter (DM), crude protein $(C P)$, ether extract (EE), neutral detergent fiber (NDF) and total digestible nutrients (TDN) of the experimental diets

\begin{tabular}{|c|c|c|c|c|c|}
\hline \multirow[t]{2}{*}{ Item } & \multicolumn{5}{|c|}{$\begin{array}{c}\text { Nível de concentrado (\%) } \\
\text { Level of concentrate }\end{array}$} \\
\hline & 25 & 37,5 & 50 & 62,5 & 75 \\
\hline $\operatorname{MS}(D M), \%$ & 88,25 & 88,22 & 87,83 & 87,71 & 88,11 \\
\hline $\mathrm{PB}(C P)^{1}$ & 8,48 & 10,82 & 13,01 & 15,28 & 16,90 \\
\hline $\mathrm{EE}^{1}$ & 1,98 & 2,14 & 2,42 & 2,75 & 3,06 \\
\hline $\operatorname{FDN}(N D F)^{l}$ & 63,12 & 53,71 & 46,34 & 36,20 & 27,69 \\
\hline $\operatorname{NDT}(T D N)^{1}$ & 63,08 & 62,51 & 67,31 & 71,33 & 75,26 \\
\hline
\end{tabular}

$1 \%$ na matéria seca (\% of dry matter). 


\section{Resultados e Discussão}

O ganho de peso, os dias de confinamento e o consumo de nutrientes foram relatados por FERREIRA et al. (1999). As médias, as equações de regressão e os coeficientes de variação referentes ao rendimento de carcaça e aos cortes da carcaça são mostrados na Tabela 2. Os rendimentos de carcaça e dos cortes foram calculados em relação a seu peso frio.

Os rendimentos de carcaça, tanto em relação ao peso vivo, quanto ao peso de corpo vazio, não foram influenciados $(\mathrm{P}>0,05)$ pelos níveis de concentrado na ração. Resultados semelhantes foram verificados por ALVES et al. (1996) e FEIJÓ et al. (1996 a e b). Por outro lado, PRESTON e WILLIS (1982) afirmaram que o aumento na proporção de concentrado tende a melhorar o rendimento de carcaça, por diminuição do conteúdo gastrintestinal. Os animais alimentados com maior proporção de concentrado na ração, apesar de terem apresentado menor peso de conteúdo gastrintestinal, apresentaram maiores pesos de órgãos internos, vísceras e gordura interna, conforme verificado por FERREIRA et al. (1998). Esse fato poderia, em parte, explicar a ausência do efeito dos níveis de concentrado no rendimento de carcaça, principalmente, em relação ao peso de corpo vazio.

Constatou-se também, por intermédio da análise de regressão, que os níveis de concentrado não influenciaram $(\mathrm{P}>0,05)$ o rendimento dos cortes básicos (Tabela 2). O mesmo comportamento foi verificado por FEIJÓ et al. (1996 a e b). Segundo PETIT et al. (1994), quando o peso de abate é pré-determinado, diferenças entre níveis de concentrado são raras para as características da carcaça.

Constam da Tabela 3 as médias, as equações de regressão e os coeficientes de regressão e determinação para o comprimento de carcaça, a área de olho de lombo e as proporções de músculo, osso e gordura da carcaça.

O comprimento da carcaça (CC) diminuiu linearmente $(\mathrm{P}<0,01)$ com o aumento da proporção de concentrado na ração. A área de olho de lombo (AOL), que é uma medida realizada no maior músculo dos cortes nobres, não foi influenciada $(P>0,05)$ pelos níveis de concentrado. Resultados semelhantes foram verificados por PETIT et al. (1994).

Tabela 2 - Médias e regressão ajustada para rendimento de carcaça em relação ao peso vivo (RCPV) ou peso de corpo vazio (RCPCV) e de cortes primários, em função dos níveis de concentrado na ração

Table 2 - Means and fitted regression of carcass yield in relation to the live weight (CYLW) or empty body weight (CYEBW) and prime cuts yield, on the dietary concentrate levels

\begin{tabular}{|c|c|c|c|c|c|c|c|}
\hline \multirow[t]{2}{*}{$\begin{array}{l}\text { Rendimento (\%) } \\
\text { Yield }\end{array}$} & \multicolumn{5}{|c|}{$\begin{array}{l}\text { Nível de concentrado (\%) } \\
\text { Level of concentrate }\end{array}$} & \multirow[t]{2}{*}{$\mathrm{CV}(\%)^{*}$} & \multirow[t]{2}{*}{$\begin{array}{l}\text { Regressão } \\
\text { Regression }\end{array}$} \\
\hline & 25 & 37,5 & 50 & 62,5 & 75 & & \\
\hline $\begin{array}{l}\text { RCPV } \\
\text { CYLW }\end{array}$ & 59,81 & 56,64 & 57,63 & 56,73 & 58,17 & 7,7 & $\hat{\mathrm{Y}}=57,8$ \\
\hline $\begin{array}{l}\text { RCPCV } \\
C Y E B W\end{array}$ & 69,93 & 64,96 & 64,83 & 63,01 & 63,94 & 7,7 & $\hat{Y}=65,33$ \\
\hline $\begin{array}{l}\text { Dianteiro } \\
\text { Forequarter }\end{array}$ & 41,63 & 41,20 & 41,83 & 42,14 & 41,32 & 3,9 & $\hat{\mathrm{Y}}=41,60$ \\
\hline $\begin{array}{l}\text { Paleta } \\
\text { Arm }\end{array}$ & 18,21 & 18,63 & 17,61 & 18,66 & 18,21 & 4,7 & $\hat{\mathrm{Y}}=18,22$ \\
\hline $\begin{array}{l}\text { Acém } \\
\text { Nech, brischet } \\
\text { and chuck }\end{array}$ & 23,43 & 22,57 & 24,22 & 23,48 & 23,25 & 8,3 & $\hat{Y}=23,84$ \\
\hline $\begin{array}{l}\text { Traseiro total } \\
\text { Hind-quarter }\end{array}$ & 58,36 & 58,81 & 58,17 & 57,86 & 56,68 & 2,7 & $\hat{\mathrm{Y}}=58,40$ \\
\hline $\begin{array}{l}\text { Traseiro especial } \\
\text { Saw cut }\end{array}$ & 46,33 & 45,89 & 44,92 & 45,16 & 47,35 & 3,5 & $\hat{Y}=45,93$ \\
\hline $\begin{array}{l}\text { Alcatra } \\
\text { Surloin }\end{array}$ & 18,91 & 18,81 & 18,40 & 17,76 & 19,45 & 7,3 & $\hat{\mathrm{Y}}=18,67$ \\
\hline $\begin{array}{l}\text { Coxão } \\
\text { Leg }\end{array}$ & 27,42 & 27,04 & 26,58 & 27,41 & 27,91 & 5,3 & $\hat{Y}=27,26$ \\
\hline $\begin{array}{l}\text { Ponta de agulha } \\
\text { Spare rib }\end{array}$ & 12,04 & 12,91 & 13,25 & 12,69 & 11,07 & 8,2 & $\hat{\mathrm{Y}}=12,39$ \\
\hline
\end{tabular}

* Coeficiente de variação (Coefficient of variation). 
1178 Rev. bras. zootec.

Tabela 3 - Médias e regressão ajustada para comprimento de carcaça (CC), área de olho de lombo (AOL) e proporções de músculo, ossos e gordura, em função dos níveis de concentrado na ração

Table 3 - Means and fitted regression of carcass length (CL), loin eye area (LEA) and muscles, bone and fat contents on the dietary concentrate levels

\begin{tabular}{|c|c|c|c|c|c|c|c|c|}
\hline \multirow[t]{2}{*}{ Item } & \multicolumn{5}{|c|}{$\begin{array}{l}\text { Nível de concentrado (\%) } \\
\text { Level of concentrate }\end{array}$} & \multirow[t]{2}{*}{$\mathrm{CV}(\%)^{*}$} & \multirow[t]{2}{*}{$\mathrm{r}^{2} / \mathrm{R}^{2}$} & \multirow[t]{2}{*}{$\begin{array}{l}\text { Regressão } \\
\text { Regression }\end{array}$} \\
\hline & 25 & 37,5 & 50 & 62,5 & 75 & & & \\
\hline $\begin{array}{l}\mathrm{CC}(\mathrm{cm}) \\
C L\end{array}$ & 133 & 136 & 132 & 131 & 124 & 4,0 & 0,72 & 1 \\
\hline $\begin{array}{l}\mathrm{AOL}\left(\mathrm{cm}^{2}\right) \\
L E A\end{array}$ & 87,04 & 94,60 & 104,6 & 84,83 & 87,04 & 3,3 & - & $\hat{\mathrm{Y}}=91,98$ \\
\hline $\begin{array}{l}\text { Músculo (\%) } \\
\text { Muscles }\end{array}$ & 59,78 & 60,57 & 58,91 & 58,95 & 57,64 & 4,8 & - & $\hat{\mathrm{Y}}=59,18$ \\
\hline $\begin{array}{l}\text { Ossos (\%) } \\
\text { Bone }\end{array}$ & 15,21 & 14,35 & 13,88 & 13,35 & 14,80 & 6,4 & 0,84 & 2 \\
\hline $\begin{array}{l}\text { Gordura }(\%) \\
\text { Fat }\end{array}$ & 25,01 & 25,01 & 25,08 & 27,21 & 27,70 & 9,1 & - & $\hat{\mathrm{Y}}=26,44$ \\
\hline
\end{tabular}

1. $\hat{\mathrm{Y}}=1,40-0,0018^{\star \star} \mathrm{C}$

2. $\hat{\mathrm{Y}}=19,63-0,23^{\star \star} \mathrm{C}+0,002 \mathrm{C}^{2}$

* Coeficiente de variação (Coefficient of variation).

** Significativo a $\mathrm{P}<0,01$ pelo teste $\mathrm{t}\left({ }^{* \star}\right.$ Significant at $P<.01$ by $t$ test).

$\mathrm{C}=$ Nível de concentrado (Level of concentrate).

As proporções de músculo (M) e gordura $(\mathrm{G})$ também não foram afetadas pelos níveis de concentrado. Resultados diferentes foram obtidos por FEIJÓ et al. (1996a), que observaram carcaças com maior musculosidade para níveis mais altos de concentrado, enquanto os níveis mais baixos proporcionaram carcaças com maior deposição de gordura. A proporção de ossos na carcaça comportou-se de forma quadrática $(\mathrm{P}<0,01)$ e a proporção mínima de ossos na carcaça foi estimada com $57,5 \%$ de concentrado na ração.

As pequenas diferenças observadas para as características de carcaça podem ser explicadas pelo peso com o qual os animais foram confinados e pela determinação de que os mesmos seriam abatidos com o mesmo peso. Considerando que bovinos mestiços são precoces, o peso no qual os animais do presente experimento foram confinados indica que os mesmos estavam iniciando a fase de terminação, na qual ocorreria maior deposição relativa de gordura e, nesta fase, o nível de concentrado só serviria para determinar o tempo até os mesmos atingirem o ponto de abate, sem, contudo, alterar as características da carcaça.

$\mathrm{Na}$ Tabela 4, são apresentadas as médias e as equações de regressão ajustadas, em função dos níveis de concentrado na ração, para os pesos absolutos (kg) dos órgãos internos, além dos coeficientes de variação (CV) e determinação $\left(\mathrm{r}^{2}\right)$. Na Tabela 5 , são apresentados os mesmos parâmetros para os pesos relativos $(\mathrm{kg} / 100 \mathrm{~kg}$ de peso corporal vazio).
Os pesos do coração e pulmão não foram influenciados $(\mathrm{P}>0,05)$ pelos níveis de concentrado. Resultados semelhantes foram verificados por SIGNORETTI et al. (1996) e PERON et al. (1993b). Segundo PERON et al. (1993b), independentemente do nível de alimentação, os pesos do coração e pulmão não são afetados, indicando que estes órgãos mantêm sua integridade e, por conseguinte, têm prioridade na utilização dos nutrientes.

Pode-se verificar, nas Tabelas 4 e 5, que os pesos do fígado, rins e baço aumentaram linearmente $(\mathrm{P}<0,05)$, em resposta à adição de concentrado na ração. De acordo com FERRELL et al. (1976), o tamanho destes órgãos está relacionado com o maior consumo de nutrientes pelo animal, especialmente energia e proteína, já que os mesmos participam ativamente no metabolismo destes nutrientes. O consumo de energia e proteína dos animais utilizados no experimento elevou-se linearmente com o aumento da proporção de concentrado na ração, conforme relato de FERREIRA (1997).

JORGE et al. (1997) observaram maior peso do fígado em animais com alimentação à vontade comparados com animais que sofreram restrições alimentares. CALIL (1978) afirmou que o jejum de dois ou mais dias em bovinos antes do abate resultou em perda de peso do fígado de até $25 \%$. SIGNORETTI et al. (1996) concluíram que o peso dos rins aumentou linearmente com a adição de concentrado na ração de bezerros holandeses. 
FERREIRA et al.

Tabela 4 - Médias e regressão ajustada para os pesos absolutos (kg) de coração, pulmões, fígado, rins e baço, em função do nível de concentrado na ração

Table 4 - Means and fitted regression of absolut weights $(\mathrm{kg})$ of heart, lungs, liver, kidney and spleen on the dietary concentrate levels

\begin{tabular}{|c|c|c|c|c|c|c|c|c|}
\hline \multirow[t]{2}{*}{ Item } & \multicolumn{5}{|c|}{$\begin{array}{c}\text { Nível de concentrado }(\%) \\
\text { Level of concentrate }\end{array}$} & \multirow[t]{2}{*}{$\mathrm{CV}(\%) * / *$} & \multirow[t]{2}{*}{$\mathrm{r}^{2}$} & \multirow[t]{2}{*}{$\begin{array}{l}\text { Regressão } \\
\text { Regression }\end{array}$} \\
\hline & 25 & 37,5 & 50 & 62,5 & 75 & & & \\
\hline $\begin{array}{l}\text { Coração } \\
\text { Heart }\end{array}$ & 1,69 & 1,75 & 1,65 & 1,67 & 1,71 & 7,6 & - & $\hat{\mathrm{Y}}=1,69$ \\
\hline $\begin{array}{l}\text { Pulmões } \\
\text { Lungs }\end{array}$ & 3,11 & 2,88 & 2,98 & 3,04 & 3,02 & 8,0 & - & $\hat{\mathrm{Y}}=3,01$ \\
\hline $\begin{array}{l}\text { Fígado } \\
\text { Liver }\end{array}$ & 5,24 & 5,71 & 5,90 & 7,0 & 6,61 & 7,4 & 0,82 & 1 \\
\hline $\begin{array}{l}\text { Rins } \\
\text { Kidney }\end{array}$ & 0,74 & 0,86 & 0,87 & 0,91 & 1,09 & 6,9 & 0,90 & 2 \\
\hline $\begin{array}{l}\text { Baço } \\
\text { Spleen } \\
\end{array}$ & 1,34 & 1,42 & 1,54 & 1,75 & 1,68 & 8,5 & 0,88 & 3 \\
\hline $\begin{array}{l}\text { 1. } \hat{Y}=4,5 \\
\text { 2. } \hat{Y}=0,5 \\
\text { 3. } \hat{Y}=1,1 \\
\star \quad \text { Signific } \\
\text { C = Nível } \\
\star * \quad \text { Coefici }\end{array}$ & $\begin{array}{l}3^{*} C \\
1^{*} C \\
2^{*} C \\
05 \text { pelc } \\
\text { ado }(L \epsilon \\
\text { ação }(C\end{array}$ & $\begin{array}{l}\text { te } t{ }^{*} \\
\text { of conc } \\
\text { cient o }\end{array}$ & $\begin{array}{l}\text { icant at } \\
\text { te). }\end{array}$ & 05] by & & & & \\
\hline
\end{tabular}

Tabela 5 - Médias e regressão ajustada para os pesos relativos (kg/100 kg de peso corporal vazio) de coração, pulmões, fígado, rins e baço, em função do nível de concentrado na ração

Table 5 - Means and fitted regression of relative weights ( $\mathrm{kg} / 100 \mathrm{~kg}$ of empty body weight) of heart, lungs, liver, kidney and spleen on the dietary concentrate level

\begin{tabular}{|c|c|c|c|c|c|c|c|c|}
\hline \multirow[t]{2}{*}{ Item } & \multicolumn{5}{|c|}{$\begin{array}{c}\text { Nível de concentrado }(\%) \\
\text { Level of concentrate }\end{array}$} & \multirow[t]{2}{*}{$\mathrm{CV}(\%)^{* *}$} & \multirow[t]{2}{*}{$\mathrm{r}^{2}$} & \multirow[t]{2}{*}{$\begin{array}{l}\text { Regressão } \\
\text { Regression }\end{array}$} \\
\hline & 25 & 37,5 & 50 & 62,5 & 75 & & & \\
\hline $\begin{array}{l}\text { Coração } \\
\text { Heart }\end{array}$ & 0,40 & 0,40 & 0,37 & 0,37 & 0,37 & 7,2 & - & $\hat{\mathrm{Y}}=0,382$ \\
\hline $\begin{array}{l}\text { Pulmões } \\
\text { Lungs }\end{array}$ & 0,74 & 0,66 & 0,67 & 0,67 & 0,66 & 6,2 & - & $\hat{\mathrm{Y}}=0,68$ \\
\hline $\begin{array}{l}\text { Fígado } \\
\text { Liver }\end{array}$ & 1,22 & 1,31 & 1,32 & 1,55 & 1,45 & 7,3 & 0,75 & 1 \\
\hline $\begin{array}{l}\text { Rins } \\
\text { Kidney }\end{array}$ & 0,17 & 0,19 & 0,19 & 0,20 & 0,24 & 6,7 & 0,83 & 2 \\
\hline $\begin{array}{l}\text { Baço } \\
\text { Spleen }\end{array}$ & 0,31 & 0,33 & 0,34 & 0,33 & 0,37 & 8,3 & 0,77 & 3 \\
\hline
\end{tabular}

1. $\hat{\mathrm{Y}}=1,09931+0,005327^{*} \mathrm{C}$

2. $\hat{\mathrm{Y}}=0,146+0,001096{ }^{*} \mathrm{C}$

3. $\hat{\mathrm{Y}}=0,28843+0,000971^{*} \mathrm{C}$

* Significativo a $(\mathrm{P}<0,05)$ pelo teste $\mathrm{t}\left({ }^{*}\right.$ Significant at $[P<.05]$ by $t$ test $)$

** Coeficiente de variação (Coefficient of variation).

C = Nível de concentrado (Level of concentrate).

Na Tabela 6, são apresentadas as médias e as equações de regressão ajustadas, em função dos níveis de concentrado na ração, para os pesos absolutos (kg) do conteúdo do TGI e dos compartimentos do TGI , além dos coeficientes de variação $(\mathrm{CV})$ e determinação $\left(\mathrm{r}^{2}\right)$. Na Tabela 7 , são apresentados os mesmos parâmetros para os compartimentos do TGI.

Nas Tabelas 6 e 7, são apresentados os mesmos parâmetros para os peso relativos $(\mathrm{kg} / 100$ de peso corporal vazio).

O conteúdo do TGI diminuiu linearmente $(\mathrm{P}<0,05)$ com o aumento do nível de concentrado na ração, o que pode ser explicado pela composição das rações experimentais (Tabela 1). As rações com menores níveis de concentrado apresentaram maiores teores de fibra e menor digestibilidade, aumentando, dessa 
1180 Rev. bras. zootec.

Tabela 6 - Médias e regressão ajustada para os pesos absolutos $(\mathrm{kg})$ do conteúdo do trato gastrintestinal (CTGI), rúmen-retículo (RURE), omaso, abomaso, intestino delgado (INTD), intestino grosso (INTG) e gordura interna (GORD), em função do nível de concentrado na ração

Table 6 - Means and fitted regression of absolut weights $(\mathrm{kg})$ of gastrointestinal tract fill (GTF), rumen-reticulo (RURE), omasum, abomasum, small intestine (SMI), large intestine (LAI) and internal fat (INTF), on the dietary concentrate level

\begin{tabular}{|c|c|c|c|c|c|c|c|c|}
\hline \multirow[t]{2}{*}{ Item } & \multicolumn{5}{|c|}{$\begin{array}{c}\text { Nível de concentrado }(\%) \\
\text { Level of concentrate }\end{array}$} & \multirow[t]{2}{*}{$\mathrm{CV}(\%)^{* *}$} & \multirow[t]{2}{*}{$\mathrm{r}^{2} / \mathrm{R}^{2}$} & \multirow[t]{2}{*}{$\begin{array}{l}\text { Regressão } \\
\text { Regression }\end{array}$} \\
\hline & 25 & 37,5 & 50 & 62,5 & 75 & & & \\
\hline $\begin{array}{l}\text { CTGI } \\
G T F\end{array}$ & 59,71 & 52,48 & 45,02 & 40,11 & 36,81 & 13,3 & 0,98 & 1 \\
\hline $\begin{array}{l}\text { RURE } \\
\text { RURE }\end{array}$ & 7,20 & 7,08 & 6,83 & 7,22 & 7,50 & 8,5 & 0,86 & 2 \\
\hline $\begin{array}{l}\text { Omaso } \\
\text { Omasum }\end{array}$ & 3,70 & 3,38 & 3,15 & 3,00 & 2,54 & 11,5 & 0,98 & 3 \\
\hline $\begin{array}{l}\text { Abomaso } \\
\text { Abomasum }\end{array}$ & 1,11 & 1,07 & 1,13 & 1,30 & 1,41 & 11,3 & 0,83 & 4 \\
\hline $\begin{array}{l}\text { INTD } \\
S M I\end{array}$ & 5,17 & 5,93 & 5,94 & 6,71 & 6,43 & 10,9 & 0,80 & 5 \\
\hline $\begin{array}{l}\text { INTG } \\
L A I\end{array}$ & 2,99 & 3,48 & 3,51 & 3,83 & 3,99 & 12,1 & 0,93 & 6 \\
\hline $\begin{array}{l}\text { GORD } \\
\text { INTF }\end{array}$ & 14,13 & 18,06 & 19,22 & 22,83 & 20,38 & 12,6 & 0,79 & 7 \\
\hline
\end{tabular}

1. $\hat{Y}=70,0527-0,4638^{*} \mathrm{C}$

2. $\hat{Y}=8,31-0,0599^{*} \mathrm{C}+0,0007^{*} \mathrm{C}^{2}$

3. $\hat{Y}=4,2365-0,0217^{\star} \mathrm{C}$

4. $\hat{Y}=0,8685+0,0067^{*} \mathrm{C}$

5. $\hat{Y}=4,7311+0,0258^{*} C$

6. $\hat{Y}=2,6221+0,0188^{*} \mathrm{C}$

7. $\hat{Y}=12,111+0,1344^{*} \mathrm{C}$

* Significativo a $(P<0,05)$ pelo teste $t\left({ }^{*}\right.$ Significant at $[P<.05]$ by $t$ test $)$.

** Coeficiente de variação (Coefficient of variation).

C = Nível de concentrado (Level of concentrate).

Tabela 7 - Médias e regressão ajustada para os pesos relativos (kg/ $100 \mathrm{~kg}$ de peso corporal vazio) do rumenretículo (RURE), omaso, abomaso, intestino delgado (INTD) intestino grosso (INTG) e gordura interna (GORD), em função do nível de concentrado na ração

Table 7 - Means and fitted regression of relative weights ( $\mathrm{kg} / 100 \mathrm{~kg}$ of empty body weight) of rumen-reticulo (RURE), omasum, abomasum, small intestine (SMI), large intestine (LAl) and internal fat (INTF), on the dietary concentrate level

\begin{tabular}{|c|c|c|c|c|c|c|c|c|}
\hline \multirow[t]{2}{*}{ Item } & \multicolumn{5}{|c|}{$\begin{array}{c}\text { Nível de concentrado }(\%) \\
\text { Level of concentrate }\end{array}$} & \multirow[t]{2}{*}{$\mathrm{CV}(\%)^{* *}$} & \multirow[t]{2}{*}{$\mathrm{r}^{2} / \mathrm{R}^{2}$} & \multirow[t]{2}{*}{$\begin{array}{l}\text { Regressão } \\
\text { Regression }\end{array}$} \\
\hline & 25 & 37,5 & 50 & 62,5 & 75 & & & \\
\hline $\begin{array}{l}\text { RURE } \\
\text { RURE }\end{array}$ & 1,68 & 1,63 & 1,53 & 1,59 & 1,65 & 4,6 & 0,84 & 1 \\
\hline $\begin{array}{l}\text { Omaso } \\
\text { Omasum }\end{array}$ & 0,86 & 0,78 & 0,71 & 0,66 & 0,56 & 2,2 & 0,99 & 2 \\
\hline $\begin{array}{l}\text { Abomaso } \\
\text { Abomasum }\end{array}$ & 0,26 & 0,25 & 0,25 & 0,29 & 0,31 & 5,9 & 0,73 & 3 \\
\hline $\begin{array}{l}\text { INTD } \\
\text { SMI }\end{array}$ & 1,21 & 1,36 & 1,33 & 1,48 & 1,41 & 4,9 & 0,67 & 4 \\
\hline $\begin{array}{l}\text { INTG } \\
L A I\end{array}$ & 0,70 & 0,80 & 0,79 & 0,85 & 0,88 & 5,8 & - & $\hat{\mathrm{Y}}=0,804$ \\
\hline $\begin{array}{l}\text { GORD } \\
\text { INTF }\end{array}$ & 0,89 & 1,28 & 1,37 & 1,71 & 1,49 & 13,5 & 0,73 & 5 \\
\hline
\end{tabular}

1. $\hat{Y}=2,0328-0,018^{*} C+0,0002^{*} C^{2}$

2. $\hat{\mathrm{Y}}=1,0028-0,00579^{*} \mathrm{C}$

3. $\hat{\mathrm{Y}}=0,2126+0,0012^{*} \mathrm{C}$

4. $\hat{\mathrm{Y}}=1,1522+0,004128^{*} \mathrm{C}$

5. $\hat{\mathrm{Y}}=0,6908+0,0131^{*} \mathrm{C}$

* Significativo a $(P<0,05)$ pelo teste $t\left({ }^{*}\right.$ Significant at $[P<.05]$ by $t$ test $)$.

** Coeficiente de variação (Coefficient of variation).

C = Nível de concentrado (Level of concentrate). 
forma, o tempo de retenção no rúmen. Por outro lado, as rações com maiores níveis de concentrado apresentaram menores teores de fibra e maior digestibilidade, resultando em menor tempo de retenção das mesmas. Este resultado está de acordo com PRESTON e WILLIS (1982) e AGRICULTURAL RESEARCH COUNCIL - ARC (1980), os quais afirmaram que a adição de concentrado na ração reduz o conteúdo do TGI. Dessa forma, a melhor maneira de expressar o ganho de peso de bovinos alimentados com diferentes níveis de concentrado na ração seria em relação ao peso de corpo vazio, para evitar a influência do conteúdo do TGI.

Os níveis de concentrado influenciaram $(\mathrm{P}<0,05)$, de forma quadrática, o peso do rúmen-retículo. Isto, em parte, pode ser explicado pelo menor consumo de matéria seca verificado para o nível de $50 \%$ de concentrado na ração, conforme relatado por FERREIRA (1997). Os menores pesos do compartimento rúmen-retículo foram estimados com 42,8 e $45 \%$ de concentrado na ração, para os pesos absoluto e relativo, respectivamente.

SIGNORETTI et al. (1996), trabalhando com vários níveis de concentrado na ração, não verificaram efeito destes sobre o peso de rúmen-retículo. Já OLIVEIRA et al. (1994) e PERON et al. (1993b) observaram maior peso de rúmen-retículo para animais alimentados à vontade, em relação àqueles com alimentação restrita. Deve-se ressaltar que, no presente trabalho, todos os animais foram alimentados à vontade.

Os pesos do abomaso e intestino delgado, nas duas formas de apresentação, e do intestino grosso, em valores absolutos, aumentaram linearmente $(\mathrm{P}<0,05)$ em resposta à adição de concentrado. Segundo FERRELL et al. (1976) e PERON (1991), os maiores pesos destes compartimentos estão associados ao maior consumo de alimentos e, conseqüentemente, ao maior aporte de nutrientes, já que os mesmos participam ativamente da digestão e absorção. Já para o peso relativo do intestino grosso, não foi verificado efeito dos níveis de concentrado $(\mathrm{P}>0,05)$.

$\mathrm{O}$ peso do omaso diminuiu linearmente $(\mathrm{P}<0,01)$ com o aumento da proporção de concentrado na ração, e os animais que receberam as maiores proporções apresentaram os menores pesos. Este resultado está de acordo com as afirmações de VAN SOEST (1994) de que ocorre involução do omaso em bovinos alimentados com dietas contendo altos níveis de concentrado.

A gordura localizada internamente (cavitária e visceral) aumentou linearmente $(\mathrm{P}<0,05)$ com a in- clusão de concentrado na ração. Este efeito pode ser atribuído ao maior consumo de energia por parte dos animais que se alimentaram com rações contendo maiores níveis de concentrado, conforme relato de FERREIRA (1997). Esta maior proporção de gordura interna acarreta, na prática, maiores exigências de energia para mantença (SOLIS et al., 1988; OWENS et al., 1995), em razão da maior atividade metabólica do tecido adiposo. Considerando-se que a gordura interna não é aproveitada para consumo humano, haveria desperdício de energia alimentar.

\section{Conclusões}

Os níveis de concentrado não afetaram os rendimentos dos cortes básicos, o rendimento de carcaça, a área de olho de lombo e as proporções de músculo e gordura da carcaça. Houve redução no comprimento da carcaça em resposta ao aumento do nível de concentrado. Houve efeito quadrático dos níveis de concentrado em relação à proporção de ossos na carcaça, estimando-se a proporção mínima de ossos com $57,5 \%$ de concentrado na ração.

Os pesos do coração e pulmão não foram influenciados pelos níveis de concentrado. Os pesos de baço, fígado, rins, abomaso, intestino delgado, intestino grosso e gordura interna aumentaram e o conteúdo do trato gastrintestinal e o peso do omaso diminuíram linearmente com a inclusão de concentrado nas dietas. $\mathrm{O}$ peso do rúmen-retículo foi influenciado quadraticamente pela inclusão de concentrado nas rações.

\section{Referências Bibliográficas}

AGRICULTURAL RESEARCH COUNCIL - ARC. 1980. The nutrient requirements of ruminants livestock. London: Commonwealth Agricultural Bureaux. 351p.

ALVES, J.B., ISEPON, O.J., BERGAMASCHINE, A.F. et al. Ganho de peso e rendimento de carcaça de bovinos guzerá submetidos a dois níveis de alimentação. In: REUNIÃO ANUAL DA SOCIEDADE BRASILEIRA DEZOOTECNIA, 33, 1996. Fortaleza. Anais... Fortaleza: SBZ, 1996. p.26-27.

BARRY, M.C., FOX, D.C., TYLUTKY, T.P. et al. 1994. A manual for using the cornell net carbohydrate and protein system for evaluating cattle diets. Revised for CNCPS release 3.ed., Ithaca, NY. 40p. (Manual).

BERG, R.T., BUTTERFIELD, R.M. 1976. New concepts of cattle growth. First edition, New York. 240p.

CALIL, R.M. 1978. Inspeção "ante morten". In: CURSO INTERNACIONAL SOBRE TECNOLOGIA DE CARNE. Campinas, ITAL. p.41.

CATTON, J.S., DHUYVETTER, D.V. 1997. Influence of energy supplementation on grazing ruminants: requirements and responses. J. Anim. Sci., 75:533-542.

FEIJÓ, G.L.D., THIAGO, L.R.L., JOBÁ, I. et al. Efeito de níveis 
1182 Rev. bras. zootec.

de concentrado na engorda de bovinos confinados. Características das carcaças de animais $\mathrm{F}_{1}$ Pardo Suiço x Nelore: REUNIÃO ANUAL DA SOCIEDADE BRASILEIRA DE ZOOTECNIA, 33, 1996. Fortaleza. Anais...Fortaleza: SBZ, 1996. p.79-81.

FEIJÓ, G.L.D., THIAGO, L.R.L., JOBÁ, I. et al. Efeito de níveis de concentrado na engorda de bovinos confinados. Características das carcaças de animais $\mathrm{F}_{1}$ Pardo Suiço x Nelore: REUNIÃO ANUAL DA SOCIEDADE BRASILEIRA DE ZOOTECNIA, 33, 1996. Fortaleza. Anais... Fortaleza: SBZ, 1996. p.76-78.

FERREIRA, M.A. Desempenho, exigências nutricionais e eficiência de utilização da energia metabolizável para ganho de peso de bovinos $F_{1}$ Simental $x$ Nelore. Viçosa, MG: UFV, 1997. 97p. Tese (Doutorado em Zootecnia) - Universidade Federal de Viçosa, 1997.

FERREIRA, M.A., VALADARES FILHO, S.C., BARBOSA, W.A. Efeito do nível de concentrado sobre o peso dos órgãos internos e conteúdo gastrointestinal de bovinos de corte. In: REUNIÃO ANUAL DA SOCIEDADE BRASILEIRA DE ZOOTECNIA, 35, 1998, Botucatu. Anais...Botucatu: SBZ, 1998, p.266-268.

FERREIRA, M.A., VALADARES FILHO, S.C., COELHO DA SILVA, J.F. et al. 1999. Consumo, conversão alimentar, ganho de peso e características da carcaça de bovinos $\mathrm{F}_{1}$ Simental x Nelore. Rev. bras. zootec., 28(2):343-351.

FERRELL, C.L., GARRET, W.N., HINMAN, N. 1976. Estimation of body composition in pregnant and non pregnant heifers. J. Anim. Sci., 42(5):1158-1166.

FERRELL, C.L., JENKINS, T.G. 1998. Body composition and energy utilization by steers of diverse genotypes fed a highconcentrate diet during the finishing period: I. Angus, Belgian Blue, Hereford, and Piedmontese Sires. J. Anim. Sci., 76:647-657.

FOX, D.G., SNIFFEN, C.J., O'CONNOR, J. D. et al. 1992. A net carbohydrate and protein system for evaluating cattle diets: III. Cattle requirements and diet adequacy. J. Anim. Sci., 70(11):3578-3596.

GEAY, Y. Live weight measurement. In: EEC SEMINAR ON CRITERIA AND METHODS FOR ASSESSMENT OF CARCASS AND MEAT CHARACTERISTICS IN BEEF PRODUCTION EXPERIMENTS, 1975, Zeist. Proceedings... snt, 1975, p.35-42.

HANKINS, O.G., HOWE, P.E. 1946. Estimation of the composition of beef carcass and cuts. Washington, USDA (Thec. Bulletin. USDA, 926).

JOHNSON, D.E., JOHNSON, K.A., BALDWIN, R.L. 1990. Changes in liver and gastrointestinal tract energy demands in response to physiological workload in ruminants. J. Nutr., 120(2):649-655.

JORGE, A.M. Ganho de peso, conversão alimentar e característica da carcaça de bovinos e bubalinos. Viçosa, MG: UFV, 1993. 97p. Dissertação (Mestrado em Zoootecnia) Universidade Federal de Viçosa, 1993.

JORGE, A.M., FONTES, C.A.A., PAULINO, M.F. Efeito da raça e do nível nutricional sobre o tamanho dos órgãos internos em zebuínos. In: REUNIÃO ANUAL DA SOCIEDADE BRASILEIRA DE ZOOTECNIA, 34, Juiz de Fora, 1997. Anais... Juiz de Fora: SBZ, 1997. p.466-468.

LANA, R.P., FONTES, C.A.A., PERON, J.A. et al. 1992. Conteúdo do trato gastrintestinal (digesta) e sua relação com o peso corporal e ganho de peso em novilhos de cinco grupos raciais e bovinos machos inteiros. R. Soc. Bras. Zootec., 21(3):511-517.
LOFGREEN, G.P., HULL, J.L. 1962. Estimation of empty body weight of beef cattle. J. Anim. Sci., 21(1):20-24.

LUNT, D.K., BYERS, F.M., GREENE, L.W. et al. 1986. Effects of breed, diet, and growth rate on vital organ mass in growing and finishing beef steers. J. Anim. Sci., 63(1):70-71, (Supplement 1).

OLIVEIRA, M.A.T., FONTES, C.A.A., LANA, R.P. et al. 1994. Biometria do trato gastrintestinal e área corporal de bovinos. R. Soc. Bras. Zootec., 23(4):576-584.

OWENS, F.N., GILL, D.R., SECRIST, D.S. et al. 1995. Review of some aspects of growth and development of feedlot cattle. J. Anim. Sci., 73(12):3152-3172.

PERON, J.A. Características e composição física e química, corporal e da carcaça de bovinos de cinco grupos genéticos, submetidos à alimentação restrita e "ad libitum”. Viçosa, MG: UFV, 1991, 126p. Dissertação (Mestrado em Zootecnia) - Universidade Federal de Viçosa, 1991.

PERON, A.J., FONTES, C.A.A., LANA, R.P. et al. 1993a. Rendimento de carcaça e de seus cortes básicos e área corporal de bovinos de cinco grupos genéticos submetidos à alimentação restrita e "ad libitum". R. Soc. Bras. Zootec., 22(2):239-247.

PERON, J.A., FONTES, C.A.A., LANA, R.P., et al. 1993b. Tamanho dos órgãos internos e distribuição da gordura corporal em novilhos de cinco grupos genéticos, submetidos à alimentação restrita e "ad libitum". R. Soc. Bras. Zootec., 22(5):813-819.

PETIT, H.V., VEIRA, D.M., YU, Y.1994. Growth and carcass characteristics of beef steers fed silage and different levels of energy with or without protein suplementation. J. Anim. Sci., 72(12):3221-3229.

PRESTON, T.R., WILLIS, M.B. 1982. Intensive beef production. 2.ed. Oxford Pergamon Press. 567p.

SIGNORETTI, R.D., ARAÚJO, G.G.L., SILVA, J.F.C. et al. Biometria do trato gastrointestinal e tamanho da massa de órgãos internos de bezerros holandeses alimentados com quatro níveis de concentrado. In: REUNIÃO ANUAL DA SOCIEDADE BRASILEIRA DE ZOOTECNIA, 33, 1996. Fortaleza. Anais... Fortaleza: SBZ, 1996. p.402-404.

SILVA, D.J. 1990. Análise de alimentos (métodos químicos e biológicos). Viçosa, MG: UFV, Imprensa Universitária. 165p.

SMITH, N.E., BALDWIN, R.L. 1974. Effects of breed, pregnancy, and lactation on weight of organs and tissues in dairy cattle. J. Dairy Sci., 57(9):1055-1060.

SOLIS, J.C., BYERS, F.M., SCHELLING, G.T. et al. 1988. Maintenance requirements and energetics efficiency of cows of different breeds types. J. Anim. Sci., 56(5):1241-1251.

TIBO, G.C. Níveis de concentrado na dieta de novilhos mestiços F1 Simental x Nelore: consumo, digestões totais e parciais e eficiência microbiana. Viçosa, MG: UFV, 1999. 78p. Dissertação (Mestrado em Zootecnia) - Universidade Federal de Viçosa, 1999.

VAN SOEST, P.J. 1994. Nutritional ecology of the ruminant. 2.ed. London. Constock Publishing Associates. 467p.

Recebido em: 09/08/1999 Aceito em: 26/11/1999 